ARTICLES

THOMAS J. BLOEM, DDS, MS; MICHAEL E. RAZZOOG, DDS, MPH;

BARBARA B. CHAMBERLAIN, DDS, MS; and BRIEN LANG, DDS, MS

\title{
Efficacy of tissue brushing as measured by the prosthodontic tissue index
}

GERIATRIC DENTISTRY

\section{The management of abused tissues is the shared responsibility of dentist and patient.}

Special Care in Dentistry

Vol. 4 No. 2 March-April 1984
C OMPLETE dentures are designed to replace lost teeth and restore comfort, function, and natural appearance. Unfortunately, the stomatognathic system does not always respond favorably to these oral substitutes.

Acute and chronic inflammatory changes of the oral mucosa beneath complete dentures are common, and the cause of these changes has been the subject of many reports. Even with the control of these etiologic variables, localized inflammatory response of the oral mucosa may continue. The management of the abused tissues is the shared responsibility of dentist and patient. Although soft bristle brushing has been considered valuable in reducing oral tissue inflammation, direct clinical evaluation of this method has lacked controlled objectivity. This study was initiated to determine the efficacy of brushing the oral mucosa of the edentulous mouth as a method of reducing soft tissue inflammation. A qualitative means of clinical evaluation, the Prosthodontic Tissue Index (PTI), was used. ${ }^{1-3}$

\section{REVIEW OF THE LITERATURE}

Reports of the adverse reactions of the supporting mucous membrane to complete dentures have appeared in the literature under many titles and terms. One of the early writers to describe these phenomena was Cahn, ${ }^{4}$ who, in 1936, referred to the condition as "denture sore mouth." Detailed clinical explanations of the changes in the mucosa have been reported under corresponding titles, like papillary hyperplasia ${ }^{5,6}$ or papillomatosis..$^{7,8}$ Others have avoided an exact diagnosis by writing about chronic irritation or inflammation associated with den- tures. ${ }^{y-16}$ However, the term most often used to describe the "denture sore mouth" has been denture stomatitis. ${ }^{17-23}$

Reports about the occurrence of changes in the oral mucosa under dentures vary. The incidence of some form of stomatitis diagnosed in the supporting oral mucosa of edentulous patients has ranged from a low of $25 \%$, reported by Nyquist, ${ }^{17}$ to a high of $97.2 \%$, observed and measured by Bloem and Razzoog. ${ }^{1,3}$ These differences may be caused by the criteria used in classifying the disease process.

Many conditions have been related to the occurrence of denture stomatitis. The main reported causes are: mechanical trauma, ${ }^{9,14,23-25}$ microbial infection, ${ }^{24.26-31}$ poor oral hygiene, ${ }^{18-27.32-35}$ continuous wearing of dentures, ${ }^{6,20136}$ allergic reactions of the oral mucosa, ${ }^{25,36}$ and systemic disease resulting in depressed tissue resistance. ${ }^{9.10 .12 .16 .36,37-42}$

Treatment of denture stomatitis has been related to the classification of the disease process (simple localized, simple diffuse, or papillary hyperplasia) and the apparent causes. Regardless of the classification or the etiologic factor, treatment success is not simple nor are the results always spectacular. In general, most advocated treatment is directed at the apparent cause of denture stomatitis and is, therefore, of a local ${ }^{11,35,44,45}$ or systemic ${ }^{46}$ nature.

Routine oral hygiene practice remains the prime preventive program for control of mucosal inflammation. Cleaning of dentures with an appropriate cleanser and scrubbing with a denture brush is good home care practice ${ }^{35}$ Brushing of the oral mucosa has been advocated by several authors as an effective treatment and preventive program. $11,35,44,45$ According to Kroon and others, ${ }^{46}$ toothbrushing 
stimulates a temperature rise in gingival and alveolar mucosa. This reaction may be caused by dilatation of the microvasculature and an increased blood flow, both of which are essential for removal of waste materials. The reactive hyperemia may partially explain why tissue brushing has an effect in reducing inflammation.

Subjective and objective methods of assessing the treatment of basal seat tissue inflammation were mentioned by Bloem ${ }^{2}$ in 1978. The focus of that work was the development of a formalized method for clinical evaluation, the Prosthodontic Tissue Index. However, the study was limited because the index criteria relied heavily on subjective evaluation. In subsequent studies, Bloem and Razzoog ${ }^{1-3}$ modified the index. In its new form, the PTI is based on the color differentiation as the measurement of inflammation. Examiners were calibrated by means of standardized photographic descriptions and written criteria noting gradations in tissue health. Training sessions were held with clinical patients until an interexaminer reliability of more than $80 \%$ was obtained in several sessions. In each segment of the edentulous arch, oral health status was scored on the basis of color change. A normal, or zero, tissue surface was pink, had normal vascularity, and a matte appearance. An area with an inflammatory status of "1" was reddened or had solitary hyperemic foci and, generally, a matte appearance. A rating of ' 2 ", applied to reddened areas with multiple hyperemic foci, and a generally glossy appearance. When the tissue was distinctly red or red-to-blue, with or without hyperemic foci, and glossy, the area was rated as a "3."

The practice of tissue brushing the oral mucosa of the edentulous patient has been considered valuable in reducing inflammation. Clinicians have recommended tissue brushing as a method of preserving the health of the denture base-supporting mucosa. ${ }^{11,35,44,45}$

Although mechanical removal of plaque can have a significant role in the prevention and control of dental disease, ${ }^{47}$ the effectiveness of toothbrushing instruction has been a controversial subject. Gjermo ${ }^{48}$ observed that an audiovisual presentation in combination with individual oral hygiene instruction was effective in reducing plaque and debris on a short-term basis. Several other investigators have confirmed that a single session of motivational activity does not alter long-term oral hygiene performance. ${ }^{4.92}$ Adams and Stanmeyer reported a continuous improvement in oral hygiene during a oneyear educational program as a result of continuous efforts in patient motivation and reinstruction in oral hygiene skills. ${ }^{53}$ The positive value of reinforcement has been reported by several investigators, ${ }^{54,55}$ and the use of models to demonstrate procedures has proved effective in teaching oral hygiene regimens. ${ }^{54}$ The reports of these and other researchers provide evidence of the desirability of incorporating these concepts into a plaque-control and tissue brushing program.

\section{METHODS AND MATERIALS}

\section{Phase 1: the initial appointment}

For this study, the chosen level of significance was $95 \%$, and a sample size of 60 patients separated into two groups was considered acceptable.$^{56,57}$ Patients were selected from a group of 100 patients at the University of Michigan School of Dentistry. The initial criterion used in patient selection was that observable clinical signs of inflammation were present in the denture-bearing mucosa. The experimental population selected were $61.6 \%$ female and $38.4 \%$ male. Availability of fewer men ( 23 of the 60 patient experimental population) is not unique. In an earlier study, Olsson and Bergman found denture stomatitis and mucosal inflammation are more frequent in women than men in a ratio of $3: 1 .^{21}$ All patients completed the School of Dentistry Medical Health Questionnaire, obtained a panoramic radiograph, and received a thorough oral examination before acceptance in the study.

\section{Intraoral photographs and PTI}

To complete the initial data gathering for the first phase, photographs were obtained and the PTI was applied. Each of the 60 patients was examined by three calibrated examiners. The PTI was assessed for the maxilla and mandible and the scores recorded.

\section{Group assignment: control and brush}

Common methods for grouping patients include single groups, matched pairs, correlated samples, two or more independent samples, and modifications of the correlated and independent samples. ${ }^{56-54}$ This latter method makes use of two groups running concurrently for specified periods. For example, one group would use a tissue brush to massage oral mucosa, while the other group would use customary home care procedures for the first test period. At the end of this first test, the group initially using the brush would be asked to return to customary methods and the second group would start tissue brushing for the second test period. Thus, the values of the independent sample and a correlated sample are compounded. Because each group is balanced to the other by either randomization or allocation, investigators can be reasonably certain that any extraneous variations in one group, inherent or caused by the passage of time, are complemented by a corresponding variation in the other group. The technique of alternating the two test conditions enhances the elimination of extraneous variables because each group is subjected to both types of home care. Each group is a correlated sample and permits more than one measurement of the same experimental subjects, thereby reducing the possibility of experiment distortion caused by individual subject variation. Furthermore, the groups are isolated at visits to minimize transference of information between groups and subsequent distortion.

\section{GERIATRIC DENTISTRY}

\section{Although mechanical removal of plaque can have a significant role in the prevention and control of dental disease, the effectiveness of toothbrushing instruction has been a controversial} issue.

Special Care in Dentistry

Vol. 4 No. 2 March-April 1984 
GERIATRIC DENTISTRY

Clinical signs of inflammation were present on the denturebearing oral mucosa of the 60 patients chosen to participate in this study.

Special Care in Dentistry

Vol. 4 No. 2 March-April 1984
During the initial appointment of phase 1, the 60 subjects were divided into groups. An attempt was made to balance each group in terms of the characteristics that influence the variable studied (brushing). At no time was denture care discussed or directed. Patients were encouraged to maintain their usual practices of prosthesis care so that mucosal brushing would remain the variable under study. Gender, age, and the amount of inflammation were considered when the subjects were separated into the two groups. Because women experience mucosal inflammation at a ratio of $3: 1$, the initial grouping was modified to include an equal number of men in each group. Therefore, the "Brush GroupPhase 1" consisted of 13 women and 12 men. The "Control Group_Phase 1" consisted of 11 men and 24 women.

\section{Brushing regimen instructions}

Each patient assigned to the "Brush Group-Phase 1 " received a soft toothbrush for use during the study. The circular scrub method of brushing was demonstrated on resilient models of the maxillary and mandibular residual ridges by a registered dental hygienist. The instructors asked the patients to demonstrate the brushing technique on the models and, with the aid of a hand mirror, the patients repeated the same technique in their own mouths. A question and answer period followed to assure that the patient completely understood what was expected. Patients were instructed to brush the tissues twice daily for $2 \frac{1}{2}$ minutes during each brushing session. If the tissues were inflamed, the patients were informed to expect minor bleeding but to continue brushing with a light touch. The patients were reappointed to return in 30 days for brushing reinstruction.

\section{Phase 1}

At the one-month recall appointment, the dental hygienist questioned the patients about the brushing program, and answered patient questions about the technique. A second brush was dispensed and again the patients were requested to demonstrate brushing first on the models, and then in their own mouths. When the patients again demonstrated the technique to the satisfaction of the instructor, they were reappointed to return in $\mathbf{3 0}$ days for evaluation.

\section{Phase 2}

At the 60-day appointment, the procedures outlined in the "group assignment" section were accomplished. Intraoral photographs were obtained and the PTI scores were recorded for all 60 patients by the three examiners. The group reassignments (control and brush) were completed and the new "Brush Group-Phase 2" received instructions on tissue brushing. The new phase 2 control group was told to resume previous, usual oral hygiene habits, and the second 60-day experiment was initiated.

After 30 days, those patients assigned to the
"Brush Group_Phase 2" returned for brushing instruction reinforcement.

\section{Phase 3}

After completion of the second 60 days of the experiment, the patients returned for evaluation. Intraoral photographs were obtained, and the 60 patients were evaluated by the three examiners using the PTI.

\section{MANAGEMENT OF DATA}

A mean PTI score by examiner was obtained for each patient at each visit by totaling the scores at all tissue sites and dividing the sum by the total number of sites in both arches. Correlation coefficients were computed using the mean PTI scores, comparing them with each examiner for the same patient at the same visit to determine interexaminer reliability. Once it was determined that there existed an acceptable statistically significant correlation between examiner scores, a new PTI mean was created for each patient for each visit by summing the three examiner mean scores for all mouth sites and dividing the figure by three. These new mean scores, reflecting the tissue evaluation of the three examiners for all mouth sites, were finally subjected to the Median and Wilcoxan statistical tests used in the data analysis.

The Median Test gives information about the likelihood of two independent groups (not necessarily of the same size) drawn from the same population. In the null hypothesis the two groups are from populations with the same median; in the alternative hypothesis, the median of one group may be different. The test may be used whenever the scores for the two groups are in an ordinal scale.

The Wilcoxan Matched-Pairs Signed-Ranks Test uses information about the direction of the differences within pairs. If the relative magnitude and the direction of the differences are considered, the power of the test is increased. The Wilcoxan test gives more weight to a pair that shows a large difference between the two conditions than to a pair that shows a small difference.

\section{RESULTS}

The objective of this study was to measure the reduction of inflammation in the supporting mucosa of edentulous patients as a result of tissue brushing.

\section{Control of the experiment}

The demographic characteristics of the edentulous patients assembled for this study are presented in Table 1. Age, gender, years dentures have been worn, whether the patient wears the dentures continually, and the years since the last dental visit are reported for the total population and the brush and control groupings. Examination of these variables shows that a reasonably representative patient sample with the factors commonly associated with denture stomatitis was used. 


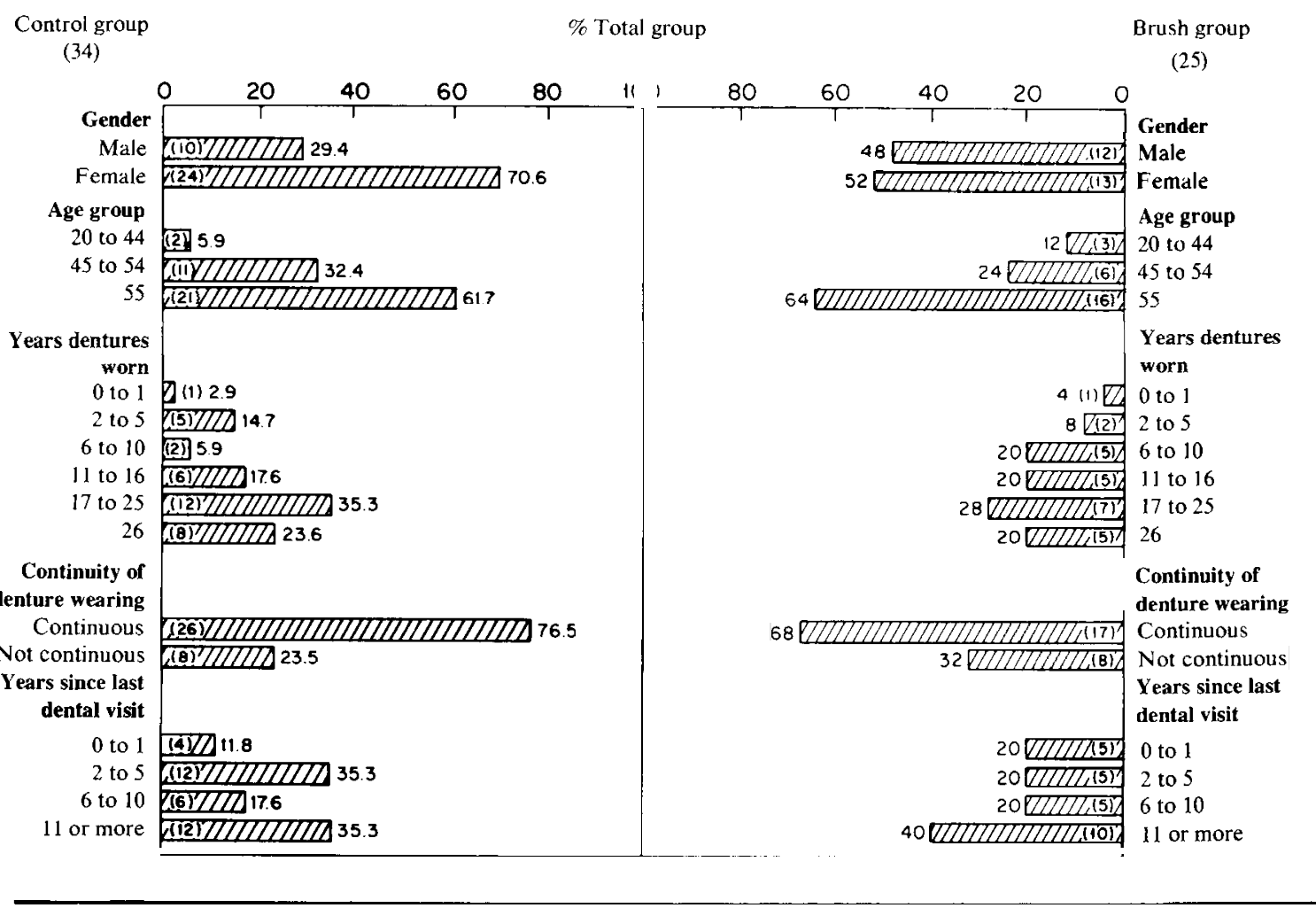

To determine that the brush and control groups used in the study were from the same original population with regard to the extent of oral mucosa inflammation, the initial or Phase 1 mean PTI scores were subjected to the Median Test and the Wilcoxan Matched Pairs Signed-Ranks statistical test.

\section{Initial group differences}

The mean PTI scores for the brush and control groups (1.22 vs 1.23 ) at the initiation of the study are presented in Table 2. After being subjected to the Median Test and the Wilcoxan Test, no statistically significant difference was found.

\section{Mean prosthodontic tissue index scores}

The results presented in Tables 3 and 4 represent the mean PTI scores for the brush and control groups. These means were statistically tested and the correlation significance reported. Significant differences in PTI scores are reported for the brush group between the first and second phases, (1.22 vs 1.03$)$, and between the first and third phases, (1.22vs .94), at the 95\% confidence level (Table 3). However, the differences in PTI scores between the second and third phases for this same patient group were not significant. The mean PTI scores for the control group, presented in Table 4 , show the significant differences reported for all three phases.

\section{DISCUSSION}

The practice of tissue brushing the oral mucosa sup- porting complete dentures has been considered valuable in reducing inflammation in these oral tissues. However, clinical data to support this premise has been lacking. A controlled study was needed to provide scientific documentation supporting visual assessment of the efficacy of tissue brushing as a method for reducing or eliminating inflammation. The experimental design of this study required the investigators to assemble a denture population with

Table 2. Mean prosthodontic tissue index scores (PTI),* start of study.

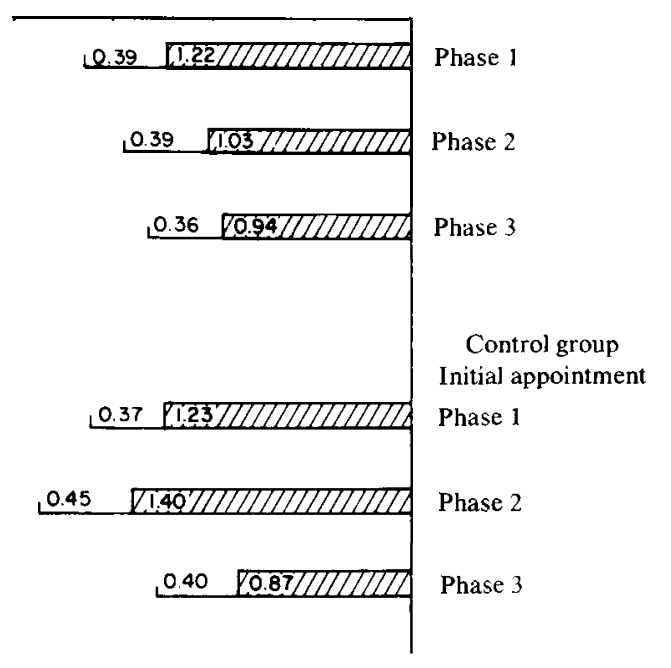

*Total mouth site scores and three examiner mean PTI scores.
GERIATRIC DENTISTRY

Special Care in Dentistry

Vol. 4 No. 2

March-April 1984 
Table 3. Mean prosthodontic tissue index scores (PTI),* brush group.

\begin{tabular}{|c|c|c|c|}
\hline \multirow[t]{11}{*}{2.0} & 1.5 & $\begin{array}{l}\text { Brush } \\
\text { Group }\end{array}$ & $\begin{array}{c}\text { Significance } \\
\text { correlation }\end{array}$ \\
\hline & $1 \quad 1 \quad 1$ & & \\
\hline & 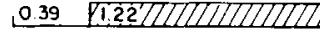 & Phase 1 & \\
\hline & & vs & $P<.05$ \\
\hline & $0.39 \quad[1.03] 201710110$ & Phase 2 & \\
\hline & $0.39 \quad 1.2271701101017001$ & Phase 1 & \\
\hline & & vs & $P<.05$ \\
\hline & 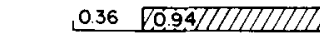 & Phase 3 & \\
\hline & 0.39 1.0370IDIDIDUD & Phase 2 & \\
\hline & & & $P>.05$ \\
\hline & 0.360 .9471011012 & Phase 3 & \\
\hline
\end{tabular}

*Total mouth site scores and three examiner mean PTI scores.

inflamed tissue beneath complete dentures. This patient group needed to demonstrate a denture health
GERIATRIC DENTISTRY profile that included those variables implicated as causative factors in oral mucosa inflammation. Years and continuity of denture use, denture age, frequency of dental visits, patient age and gender, and oral hygiene habits were considered. Before the study began, it was necessary to determine the status of these variables for each patient so that the assignment to either the control or brush group at the initial appointment provided a balance to each group and thus, more reliable comparisons during the study.

\section{Inflammation reduction}

The PTI scores for each patient were compared at the beginning and the end of each phase of the investigation to provide scientific documentation support-

Table 4. Mean prosthodontic tissue index scores (PTI), ${ }^{*}$ control group.

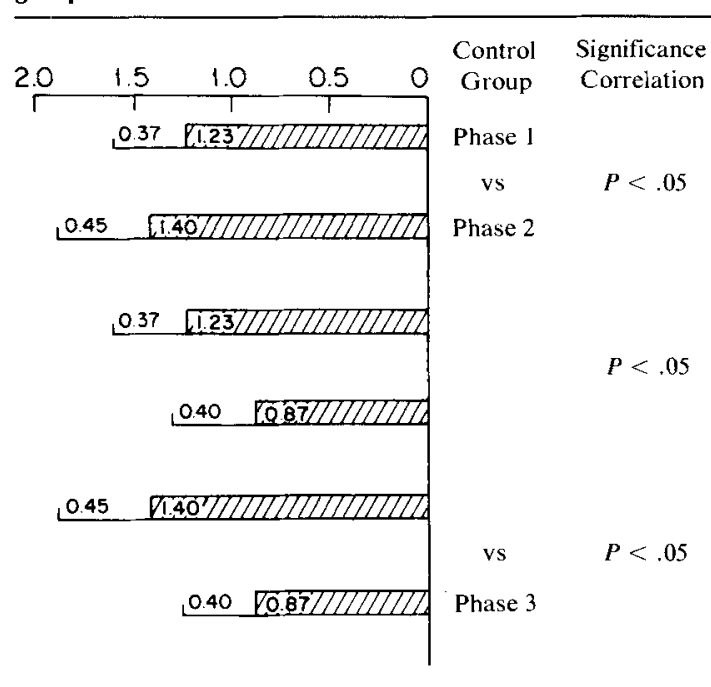

Vol. 4 No. 2 March-April 1984 ing the efficacy of tissue brushing as a method for eliminating or reducing inflammation. Table 3 shows the mean PTI scores for the total mouth and all three examiners for those patients initially assigned to brushing. The significant difference in PTI scores between Phase 1 and Phase $2(P=<.05)$ indicates that the treatment activity of brushing had reduced the oral mucosal inflammation. When these same patients were asked to return to their usual methods of home care at the start of Phase 2 and to continue this activity for the next 60 days, the index scores continued to decrease. The lower scores at Phase 3 however, were not significantly different from those at the beginning of Phase $3(P=>.05)$. Apparently brushing had a latent effect in these patients. Also, because some patients reported improved oral comfort with brushing, we suspect these individuals continued tissue brushing to some extent.

The overall effects of brushing can be seen by comparing the scores at Phase 1 with Phase 3, which show significant, favorable difference $(P=<.05)$.

The results for those patients initially assigned to the control group are shown in Table 4. Although significant difference ( $P=<.05$ ) exists between Phase 1 and Phase 2 PTI scores for this group, the tissue changes were not favorable. At the beginning of Phase 2, the initial control group began brushing and at Phase 3 the mean PTI scores reflected a significant difference. The higher index scores at Phase 2 might be regarded as the factor that created the large difference at Phase 3. However, when the scores at Phase 1 are compared with those at Phase 3 , a significant difference $(P=<.05)$ is again noted. Apparently the oral condition of patients monitored for the first 60 days using their usual home care either remained unchanged or declined. This control group phenomenon is regarded as confirmation that separation of the initial control and brush groups at the phased intervals prevented any transference of effect between groups. When these same patients began brushing in Phase 2 , the tissue responded favorably and the inflammation was substantially reduced.

\section{SUMMARY}

This study was conducted to determine the efficacy of brushing the oral mucosa supporting complete dentures with a soft brush to see if this treatment would reduce inflammation.

The oral mucosa health status of 60 patients was monitored for 120 days using the PTI to measure inflammation. For comparison the patients were divided into two groups, and every effort was made to balance the groups for those variables that may effect inflammation. The patients were also compared with themselves. The experiment consisted of three phases; Phase 1 established baseline data, and Phases 2 and 3 were information-gathering sessions. Each patient received brushing instructions at the start of the brushing test period and additional brushing instruction during a reinforcement session after 
30 days. Tissue brushing did reduce the inflammation index of the oral mucosa examined.

\section{CONCLUSIONS}

Within the constraints of this study, the following conclusions can be made: a statistically significant improvement was observed in the oral mucosa of completely edentulous patients who followed a home care regimen of tissue brushing for 60 days, as measured by the PTI. The confidence level was $P=$ 05. The Prosthodontic Tissue Index was determined to be valid and reliable, with significant interexaminer correlation coefficients.

This project was supported by the Block Drug Co, Inc.

The authors thank Drs. Steven Bernier and Marvin Novetsky, and Joan McDowen, RDH, for their assistance.

Dr. Bloem is assistant professor, complete denture department and department of hospital dentistry; Dr. Razzoog is associate professor, complete denture department and department of community dentistry; Dr. Chamberlain is assistant professor, complete denture department and department of hospital dentistry; and Dr. Lang is professor and chairman, complete denture department, the University of Michigan, School of Dentistry, Ann Arbor, 48109. Requests for reprints should be addressed to Dr. Bloem.

1. Bloem, T.J., and Razzoog, M.E. Evaluation of denturesupporting tissue health. IADR Abstracts, no. 59, p 784, 1981.

2. Bloem, T.J. A prosthodontic tissue index (PTI) for the evaluation of denture-supporting tissue health: a method study. Thesis, University of Michigan, 1978, pp vi, 54.

3. Bloem, T.J., and Razzoog, M.E. An index for the assessment of oral health status in the edentulous population. Spec Care Dent 2(3): 121-124; 2(4): 123-124, 1982.

4. Cahn, L.R. The denture sore mouth. Ann Dent 3(1):33-36, 1936.

5. Fisher, A.K., and Rashid, P.J. Inflammatory papillary hyperplasia of the palatal mucosa. Oral Surg 5(2): 191-198, 1952.

6. Tucker, K.M., and Heget, H.S. The incidence of papillary hyperplasia. JADA 93(3):610-613, 1976.

7. Bhaskar, S.N. Oral lesions in the aged population: a survey of 785 cases. Geriatrics 23:137-149, 1968.

8. Shafer, W.G.; Hine, M.K.; and Levy, B.M. A textbook of oral pathology, ed 3. Philadelphia, W. B. Saunders Co, 1974, pp 505-508.

9. Kimball, H.D. Factors to be considered in the control and elimination of chronic tissue soreness beneath dentures. J Prosthet Dent 4(3):298-311, 1954

10. Massler, M. Geriatrics and gerodontics. NY J Dent 26(2):54-63, 1956.

11. Kingery, R.H. Postinsertion phase of denture treatment. Dent Clin North Am 343-358, July 1960.

12. Vinton, P.W. Geriatric complete denture patients. Dent Clin North Am 759-772, November 1964.

13. Heartwell, C.M., Jr. Complete denture failures related to improper interpretation and improper preparation of the anatomy of the mouth. Dent Clin North Am 16(1):127-144, 1972.

14. Miller, E.L. Denture-induced inflammation. J Dent Assoc South Africa 30:89-93, 1975.

15. Welker, W.A. Prosthodontic treatment of abused oral tissues. J Prosthet Dent 37(3):259-263, 1977.

16. Nater, J.P., and others. Etiologic factors in denture sore mouth syndrome. J Prosthet Dent 40(4):367-373, 1978.

17. Nyquist, G. Study of denture sore mouth. An investigation of traumatic, allergic, and toxic lesions of the oral mucosa arising from the use of full dentures. Acta Odontol Scand (Suppl) 10:11$154,1952$.

18. Budtz-Jorgensen, E., and Bertram, U. Denture stomatitis.
The etiology in relation to trauma and infection. Acta Odontol Scand 28:71-92, 1970.

19. Kaaber, S., and Bertram, U. Cytology of the inflammatory exudate in denture stomatitis. Scand J Dent Res 79:81-91, 1971 .

20. Sheppard, I.M.; Schwartz, L.R.; and Sheppard, S.M. Oral status of edentulous and complete denture-wearing patients. JADA 83(3):614-620, 1971.

21. Olsson, K., and Bergmann, B. A comparison of two prosthetic methods for treatment of denture stomatitis. Acta Odontol Scand 29:745-753, 1971.

22. Kotilainen, R. Denture stomatitis. A clinical mycological and histologic investigation of maxillary denture wearers after a prolonged use of the denture. Proc Finnish Dent Soc (Suppl) 73:10-11, 1-72, 1977 .

23. Slabbert, J.C. The etiology and treatment of denture stomatitis. Diastema 6:4-7, 1978

24. Budtz-Jorgensen, E. Denture stomatitis. Histopathology of trauma and candida-incuced inflammatory lesions of the palatal mucosa. Acta Odontol Scand 28:551-579, 1970.

25. Braun, J.M., and Shotwell, J.L. An evaluation of a polyvinyl occlusal splint for improving the health of inflamed maxillary supporting mucosa of complete denture patients. J Prosthet Dent 42(6):614-618, 1979

26. Budtz-Jorgensen, E., and Bertram, U. Denture stomatitis. The effect of antifungal and prosthetic treatment. Acta Odontol Scand 28:283-304, 1970.

27. Davenport, J.C. The oral distribution of candida in denture stomatitis. Br Dent I 129(4):151-156, 1970.

28. Budtz-Jorgensen, E.; Stenderup, A.; and Grabowski, M. An epidemiologic study of yeasts in elderly denture wearers. Community Dent Oral Epidemiol 3(3):115-119, 1975.

29. Olsen, I. Denture stomatitis. Relapse tendency and remova of acquired discolorations in long-term denture disinfection with chlorhexidine. Acta Odontol Scand 33(2):111-114, 1975.

30. Budtz-Jorgensen, E. Clinical aspects of candida infections in denture wearers. JADA 96(3):474-479, 1978.

31. Renner, R.P., and others. The role of C. Albicans in denture stomatitis. Oral Surg 47(4):323-328, 1979.

32. Langwell, W.H. Cleansing of artificial dentures. Br Dent J $99(10): 337-339,1955$.

33. Landa, J.S. Trouble shooting in complete denture prosthesis. Factors of oral hygiene, chemotoxicity, nutrition, allergy, and conductivity. J Prosthet Dent 10(5):887-890, 1960.

34. Neill, D.J. A study of materials and methods employed in cleaning dentures. Br Dent J 124(3):107-115, 1968.

35. Koran, A., and Lang, B. R. Preparation of the oral tissues for complete denture construction. Mich Dent Assoc J 56(11):312-315, 1974.

36. Love, W.D.; Groska, F.A.; and Mixson, R.J. The etiology of mucosa inflammation associated with dentures. J Prosthet Den 18(6):515-527, 1967

37. Margolese, M.S. The role of endocrines in prosthodontics. J Prosthet Dent 23(6):607-611, 1970

38. United States Public Health Service, National Center for Health Statistics. Life tables, vital and health statistics, vol 5 Washington, DC, US Government Printing Office, 1976.

39. Burket, L.W. Burke1's oral medicine: diagnosis and treatment, ed 7. Lynch, M.A., ed. Philadelphia, J. B. Lippincott Co, 1977, p 776.

40. Kimball, H.D. Health and systemic factors involved in complete denture construction. An approach to controlling chronic tissue soreness beneath dentures. Dent Clin North Am 241-257, July 1960 .

41. Barone, J.V. Nutrition-phase one of the edentulous patient. J Prosthet Dent 40(2):122-126, 1978.

42. Siskind-Houle, B. The dental hygienist's role in care of the elderly. Dent Hyg 53(11):507-512, 1979.

43. Chase, W.W. Tissue conditioning utilizing dynamic adaptive stress. J Prosthet Dent 11(5):804-815, 1961.

44. Woods, V. Management of postinsertion problems. Dent Clin North Am 735-748, November 1964.

45. Fletcher, A.M. The treatment of denture stomatitis. Apex 11(3):97-100, 1979

46. Kroone, H., and others. Effect of toothbrushing stimulation on temperature of gingival and alveolar mucosa. J Oral Rehabil 7(2):97-102, 1980.
GERIATRIC DENTISTRY

Participants in the study were divided into two groups and were encouraged to maintain their usual practices of prosthesis

care.

Special Care in Dentistry

Vol. 4 No. 2 March-April 1984 
47. Emler, B.F., and others. The value of repetition and reinforcement in improving oral hygiene performance. $\mathbf{J}$ Periodontol 51(4):228-234, 1980.

48. Gjermo, P. Audiovisual motivation and oral hygiene instrucGERIATRIC tion. The effect upon gingival status and oral cleanliness in 15 year DENTISTRY old children. Odontol Rev 23(2):253-262, 1972.

49. Shiller, W.R., and Dittmer, J.C. An evaluation of some current oral hygiene motivational methods. J Periodontol 39(2):83-85, 1968.

50. Podshadley, A.G., and Schweikle, E.S. The effectiveness of two educational programs in changing the performance of oral hygiene by elementary school children. J Public Health Dent 30(1): $17-20,1970$.

51. Podshadley, A.G., and Shannon, J.H. Oral hygiene performance of elementary school children following dental health education. J Dent Child 37:298-300, 1970.

52. Zaki, H.A., and Bandt, C.L. The effective use of a selfteaching oral hygiene manual. J Periodontol 45(7):49\}-495, 1974.

53. Adams, R.J., and Stanmeyer, W.R. The effects of closely supervised oral hygiene program upon oral cleanliness. J Periodontol 31(3):242-245, 1960.

54. Zaki, H.A., and Bandt, C.L. Model presentation and reinforcement. An effective method for teaching oral hygiene skills. J Periodontol 41(7):394-397, 1970.

55. Stacy, D.; Abbott, D.M.; and Jordan, R. D. Improvement in oral hygiene as a function of applied principles of behavior modification. J Public Health Dent 32(4):234-242, 1972.

56. Chilton, N.W.; Dido, A.; and Rothner, J.T. Comparison of the clinical effectiveness of an electric and a standard toothbrush in normal individuals. JADA 64(6):777-782, 1962.

57. Chilton, N.W.; Sternberg, S.; and Fertig, J.W. Studies in the design and analysis of dental experiments. J Dent Res 42(1):54-62, 1963.

58. Sternberg, S.; Fertig, J.W.; and Chiton, N.W. Studies in the design and analysis of dental experiments. J Dent Res 42(1): 146153,1963

59. Smith, W.A., and Ash, M.M. A clinical evaluation of an electric toothbrush. J Periodontol 35(2):127-136, 1964.

\section{ACCESS PROGRAMS MOVE TOWARD COMPREHENSIVE CARE}

According to the 1983 Access Programs Survey, from the ADA Council on Dental Health and Health Planning, since 1981 dental societies have moved toward comprehensive care access programs instead of limiting programs to denture care.

With all 53 constituent dental societies responding to the survey, the Council determined that 30 constituent society programs provided a full range of dental care services; of the 311 component societies that responded to the survey, $48 \mathrm{had}$ programs that provide a full range of services. These figures represent an approximate $40 \%$ increase over the 1981 survey findings.

The 1983 results also show that almost every state has established either a constituent or a component access program. According to Kris Warren, the Council's assistant secretary, dentists in the seven states that did not develop formal access programs have acted on an individual basis to provide access to care to underserved populations.

Although most programs are geared toward the elderly, 12 constituent and 23 component programs were identified as directed to persons with handicapping conditions, those who are living in institutions, or patients living in remote areas. In 1981, only eight component programs were established to care for these special populations.

The most common method of increasing access ( 43 constituent and 52 component programs) is to offer fee reductions. Seven constituent and 16 component programs offer transportation assistance. Three constituent and nine component society programs use portable dental equipment.

Although the private practice office is the most common location for delivery of care, in 1983, 12 constituent programs reported long-term care facilities as an additional site for care delivery. Thirteen percent of the component societies identified hospital settings are part of their programs. 